Research Article

\title{
Research on the Settlement Regulation and Stability of Large Building Foundation over Gobs: A Case Study in the Xiangcheng Coal Mine, China
}

\author{
Wenyan Guo $\mathbb{D}^{1,2}$ Bingnan $\mathrm{Hu}\left(\mathbb{D},{ }^{2}\right.$ Junying Zhang $\mathbb{D}^{1},{ }^{1}$ Qingtong Chen $\mathbb{D},{ }^{1}$ Xinguo Jia $\mathbb{D}^{1}$, \\ and Jianghua $\operatorname{Li} \mathbb{D}^{1}$ \\ ${ }^{1}$ Mine Safety Technology Branch, CCTEG China Coal Research Institute, Beijing 100013, China \\ ${ }^{2}$ China Coal Research Institute, Beijing 100013, China \\ Correspondence should be addressed to Wenyan Guo; gwystc1205@163.com
}

Received 5 February 2021; Accepted 26 April 2021; Published 11 May 2021

Academic Editor: Chao Xu

Copyright (C) 2021 Wenyan Guo et al. This is an open access article distributed under the Creative Commons Attribution License, which permits unrestricted use, distribution, and reproduction in any medium, provided the original work is properly cited.

\begin{abstract}
Due to the acceleration of urbanization in China, the land use and new building construction in mining subsidence areas are increasing. However, a large high-rise building $(100 \mathrm{~m} \times 80 \mathrm{~m} \times 100 \mathrm{~m})$ was planned to be built above gob areas in the Xiangcheng Mine subsidence area. According to the analysis of the borehole exploration data, borehole TV observations, and theoretical calculations, there were broken bedrock and developmental fractures in the fracture and caved zones above the gob areas. In addition, the depth affected by the building load is less than $9 \mathrm{~m}$ from the top of the fracture zone; thus, the stabilities of the gobs are low. Then, through the theoretical analysis of the space stress, compression settlement of foundation soil, and residual settlement of the gob and coal pillar under loads, combining the similar simulation study on settlement characteristics of foundation soil and gobs, the total settlement of the foundation can be regarded as the vector superposition of the compression settlement and residual settlement; then, the maximum settlement is calculated as $555 \mathrm{~mm}$ and the maximum tilt is $14.9 \mathrm{~mm} / \mathrm{m}$ under the building load, which are greater than the permissible values of $200 \mathrm{~mm}$ and $2 \mathrm{~mm} / \mathrm{m}$, indicating that the foundation's stability is inadequate. Therefore, the treatment measures of the deep pile group foundations in the soil layer and grouting reinforcement in the gobs were simultaneously put forward to effectively improve the stability of the building foundations.
\end{abstract}

\section{Introduction}

An increasing number of mining subsidence areas are created due to the high intensity and large-scale mining of coal resources. According to the statistics from 2017, there has been more than $20,000 \mathrm{~km}^{2}$ of subsidence areas in China, involving the construction of $5000 \mathrm{~km}^{2}$ of urban and rural land, which seriously impacts the sustainable development of mining areas after resource depletion. With the acceleration of urbanization and modernization, land resource reuse and construction reclamation in subsidence areas are crucial $[1,2]$. Some examples of such residential area reconstruction include the Beipiao mining area and photovoltaic power generation in the Datong mining area. However, destruction to the new buildings or structures constructed above gob areas has also occurred, such as settling, tilting, cracking, or collapse [3]. Some scholars [4-8] have studied the instability of gobs and foundations and put forward failure laws. They found that the residual deformation and instability of gobs are the crucial factors contributing to that destruction. Some scholars [9-12] have researched the movement and destruction of the overlying strata in longwall mining, which can generally be divided into the caved zone, fracture zone, and continuous deformation zone (shown in Figure 1). Research shows that, in the caved zone, the rocks are severely broken and fall to the coal floor with irregular shapes, and a large degree of collapse occurs in the middle of the gob, but some unfilled cavities exist near the boundary. And in the fracture zone, the rocks break into blocks, horizontal and vertical fractures are 
developed, and the separation is severe; however, near the top, the rock strata are relatively complete, and separation and fractures decrease. Some scholars [14-17] found that residual rock fractures and cavities are still present in the gob areas, as observed by drilling detection, caving rock mass is continuously compacted, and the surface is generating continuous settlement and deformation even after a long period through monitoring. References $[18,19]$ pointed out that when these fractures and cavities and residual pillars in the gob are influenced by the building load (shown in Figure 1); they would accelerate the movement of the unstable bedrock and the settlement of unstable coal pillars, thereby causing the destruction of the new building foundation.

The Huaibei Mining Group has produced more than 1 billion tons of coal resources, resulting in a large-scale mining subsidence area. Huaibei Mining Group planned to construct an office building and residential buildings above the gobs at the Xiangcheng Mine. Unlike low-rise residential buildings, the office building was uniquely built as a large building (designed size of $100 \mathrm{~m} \times 80 \mathrm{~m} \times 100 \mathrm{~m}$ ). The range of the foundation would span three gob areas; moreover, the gobs were shallowly buried (from 90 to $115 \mathrm{~m}$ ) with thick loose layers and thin bedrock, and the range affected by the building load was large. Thus, the additional stress transferred into the soil, fracture, and caved zones, causing instability of the gobs and building foundation. Therefore, studying the regularity of foundation settlement of large buildings is very important for analyzing foundation's stability, selecting effective treatment measures, and ensuring construction safety.

Currently, many scholars [20-23] have researched the evaluation methods (such as mechanical analysis, similarity and numerical simulations, and nonlinear analysis) for the stability of foundations. However, related field studies on large buildings are insufficient in previous evaluations, especially for the study on the nonuniform settlement of foundation soil and gobs under the large-scale and highstrength load. In this paper, according to the field exploration, mechanical analysis, similarity simulation, and the establishment of settlement models, the effects of different settlement and deformation of the building foundation due to gob areas and coal pillars under the large building load are analyzed, a prediction formula for the settlement and deformation of the large building foundation is developed, and then the stabilities of the gobs and foundation are studied. Finally, effective governance measures are proposed. Different from the previous research on the grouting reinforcement of large foundation by the author himself [13], this paper enhances the theoretical research on the stability of large building foundations, improves the evaluation method of gob areas, and provides a good case for the similar constructions in mining subsidence areas.

\section{Exploration of the Gobs and Analysis of Overlying Rock Structure}

2.1. Distribution of Gobs. The construction site (delimited range of approximately $400 \mathrm{~m} \times 380 \mathrm{~m}$ ) and office building were located in seven mining areas of the Xiangcheng coal mine (shown in Figure 2). There were mainly seven gobs (shown in Figure 2); only one layer of coal seam was mined for more than 30 years, with strike longwall blast mining, dip angles of 2 to $8^{\circ}$, an average mining height of $2.5 \mathrm{~m}$, a width of 20 to $100 \mathrm{~m}$, and a buried depth of 90 to $115 \mathrm{~m}$. And the width of the coal pillars between gob was from 2 to $43 \mathrm{~m}$.

\subsection{Exploration and TV Imaging Test of the Boreholes.} There were mainly six exploration boreholes constructed in gobs (shown in Figure 2). Four boreholes (K1, K2, K3, and K6) were located near the center of the gobs, others were close to the boundary, and all the boreholes incurred wind inhalation or drill felling in the process of drilling, deducing that the rocks were broken and residual cavities existed when being near the boundary.

Based on the drilling exposure of boreholes, the thickness of the loose layer is approximately 66 to $74 \mathrm{~m}$, and the layers are mainly sandy clay, clay, and sand. The thickness of weathered bedrock is approximately 9 to $15 \mathrm{~m}$, mainly for weathered mudstone and weathered sandstone. The thickness of unweathered bedrock is approximately 12 to $28 \mathrm{~m}$, mainly for sandstone and mudstone. The buried depth of the coal seam is 89 to $107 \mathrm{~m}$.

According to the drilling core, the weathered bedrock (depth from 70 to $82 \mathrm{~m}$ ) was seriously weathered, and fractures were less developed. In the upper sandstone layer (depth from 82 to $88 \mathrm{~m}$ ), the rock blocks were more complete and had fewer fractures. However, at the bottom of the sandstone layer and the mudstone below (depth from 88 to $97 \mathrm{~m}$ ), the rock blocks were broken and incomplete, and fractures were developed. The bottom of the bedrock was mainly mudstone (depth from 97 to $110 \mathrm{~m}$ ), the rock blocks were fragmented, and more cavities were present; thus, the bottom bedrock was located in the caved zone. Based on the mechanics' test of the rock samples, the compressive strengths of the sandstone and mudstone were less than $20 \mathrm{MPa}$, indicating that the strength of the bedrock was weak. Thus, the bedrock was prone to occurring large settlement and deformation when being under the large building load.

Based on the observed results of the borehole TV imaging test, the fractures had more developed (depths from 83 to $94 \mathrm{~m}$ ) and rock mass had collapsed (depths from 94 to $102 \mathrm{~m}$ ) in the fracture zone and caved zone. Some images of the K6 borehole (depths from 87.1 to $104.5 \mathrm{~m}$ ) are shown in Figure 3; the observation results of other borehole images are similar. Vertical fractures developed, and rock collapsed from $98.6 \mathrm{~m}$ to a location close to the gob in the caved zone. Therefore, there were still rock fractures and cavities in the gob areas.

2.3. Analysis of the Bedrock Structure of a Gob. According to the observation results of rock characteristics and borehole TV imaging tests, the bedrock structure can be divided into weathered bedrock, sandstone layers, and collapsed mudstone (as immediate roofs) from top to bottom (shown in Figure 4). The weathered bedrock was broken, with low 


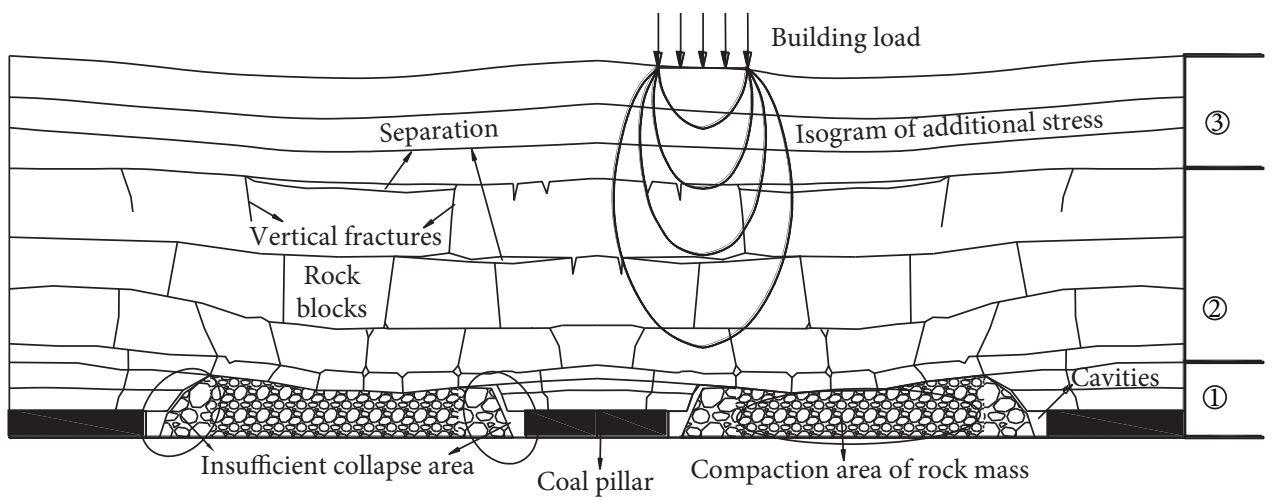

Figure 1: Zones of overlying strata in longwall mining. (1) Caved zone; (2) fracture zone; (3) continuous deformation zone (modified from $[13])$.

bearing capacity and in a state of compression, so it had few fractures. The fracture zone developed to the top of the sandstone based on observations; thus, the sandstone layer broke into blocks, but with relatively high strength and strong bearing capacity. According to the key layer theory [24], the sandstone layer can be used as the main key layer to directly affect the movement of the rock and soil above it. The strength of the immediate roof of the mudstone was low, and it collapsed during mining, so the rock mass broke more. The drilling detection results show that there are still a certain range of cavities and fractures in the rock mass of the caved zone in the middle of the gob, and the range increases near the boundary of the gob, which is the main space for the residual settlement of the gob.

\section{Nonlinear Settlement of the Gob and Residual Coal Pillar under Loads}

\subsection{Distribution of the Additional Stress Field of the Large Building Foundation}

3.1.1. Additional Stress of the Foundation. The additional stress of the foundation is caused by the building load, which can cause compression settlement of the foundation. The office building uses rectangular deep foundation; thus, the additional stress of the foundation can be calculated by the Mindlin solution method [25]. The vertical additional stress ( $\sigma_{f z}$ for short) generated by the uniformly distributed load below the corner point of the rectangular foundation at depth $z$ can be calculated using formula (1).

$$
\left\{\begin{array}{l}
\sigma_{f z}=\frac{P}{4 \pi(1-\mu)}\left[(1-\mu)\left(\tan ^{-1} \frac{a b}{z_{1} R_{1}}+\tan ^{-1} \frac{a b}{z_{2} R_{2}}\right)+\frac{a b z_{1}\left(R_{1}^{2}+z_{1}^{2}\right)}{2 r_{1}^{2} r_{3}^{2} R_{1}}+\frac{\left.a b\left[z_{0}+(3-4 \mu) z\right)\right]\left(R_{2}^{2}+z_{2}^{2}\right)}{2 r_{2}^{2} r_{4}^{2} R_{2}}+\frac{a b z_{0} z z_{2}}{R_{2}^{3}}\left(\frac{2 R_{2}^{2}+r_{2}^{2}}{r_{2}^{4}}+\frac{2 R_{2}^{2}+r_{4}^{2}}{r_{4}^{4}}\right)\right]=P \alpha_{z} \\
z_{1}=\left(z-z_{0}\right) \\
z_{2}=\left(z+z_{0}\right) \\
R_{1}{ }^{2}=a^{2}+b^{2}+z_{1}^{2} \\
R_{2}^{2}=a^{2}+b^{2}+z_{2}^{2} \\
r_{1}^{2}=a^{2}+z_{1}^{2} \\
r_{2}^{2}=a^{2}+z_{2}^{2} \\
r_{3}^{2}=b^{2}+z_{1}^{2} \\
r_{4}{ }^{2}=b^{2}+z_{2}^{2}
\end{array}\right.
$$




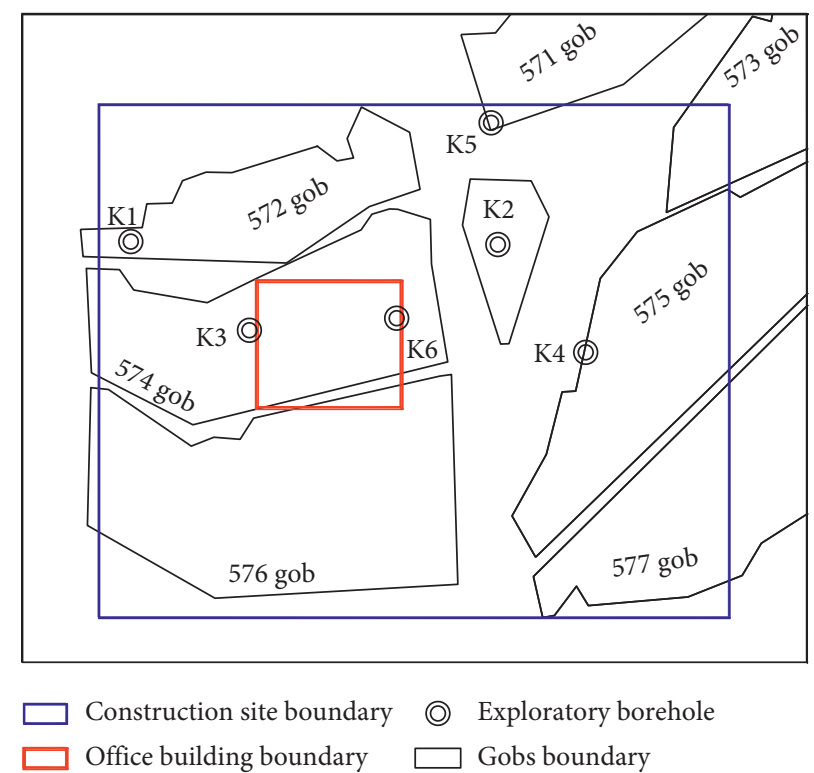

FIGURE 2: Location of the gobs, construction site, and office building (modified from [13]).

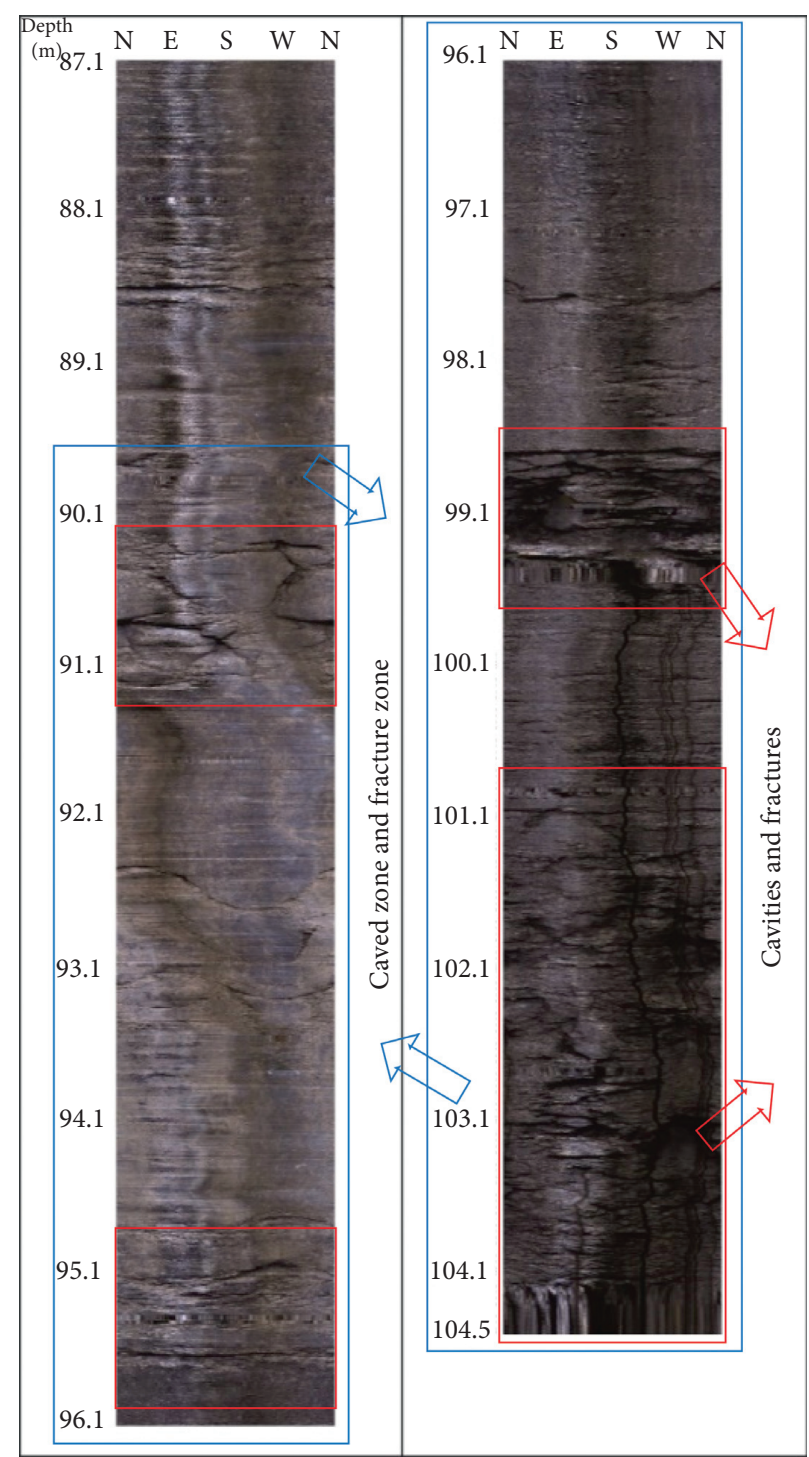

Figure 3: Parts of TV images of the K6 borehole. 


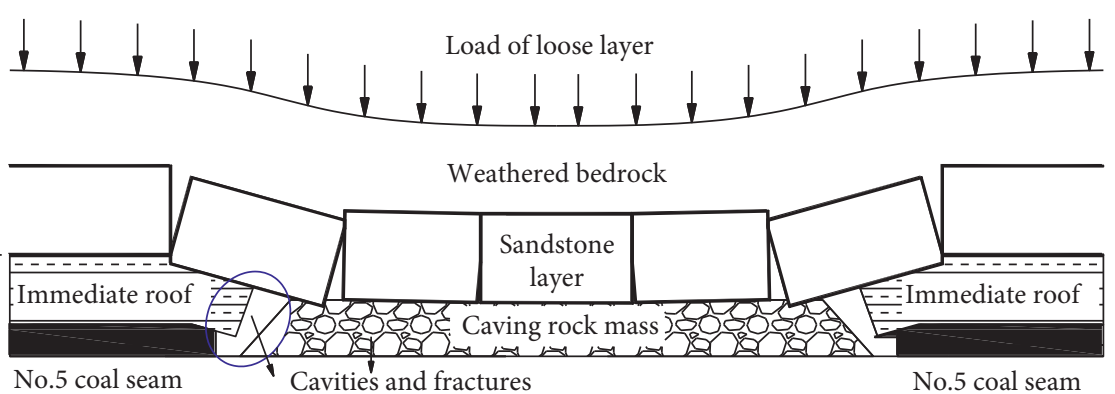

FIGURE 4: Bedrock structure of the weathered bedrock, sandstone layer, and collapsed mudstone.

where $a$ is the length of the rectangle, $b$ is the width of the rectangle, $z_{0}$ is the depth of building foundation, $\alpha_{z}$ is the additional stress coefficient of the point $(0,0, z), P$ is the uniform load, $\mu$ is Poisson's ratio of the soil, $z_{1}, z_{2}, R_{1}, R_{2}, r_{1}$, $r_{2}, r_{3}$, and $r_{3}$ are the variable symbols.

The additional stress at any point in the foundation under the rectangular uniform load can be obtained by using the additional stress at the corner through the superposition principle. The magnitude and distribution of the additional stress are positively correlated with the additional stress coefficient, and the coefficient of any point can be initially and quickly calculated by programming with MATLAB software.

3.1.2. Spatial Distribution of the Additional Stress of the Building Foundation. The length and width of the rectangular foundation of the office building are $100 \mathrm{~m} \times 80 \mathrm{~m}$, the foundation depth is $10 \mathrm{~m}$, and Poisson's ratio of the soil is 0.3 . The contour map of the additional stress coefficient in the planes (for $z$ equal to $15 \mathrm{~m}, 40 \mathrm{~m}$, and $70 \mathrm{~m}$ ) was drawn (shown in Figures 5(a)-5(c)), in which the rectangular frame signifies the foundation boundary.

The additional stress coefficient decreases from the center to the surroundings and outside of the rectangular boundary in the horizontal direction. The smaller the depth, the smaller the attenuation degree of the coefficient in the central region; thus, the higher the additional stress concentration, the more uniform the plane stress, but the greater the change degree at the positions near the two sides of the rectangular boundary, which is prone to uneven settlement. With increasing vertical depth, the additional stress coefficient decreases, and the effect of the load on the soil is reduced, but the influence range increases. At a depth of $70 \mathrm{~m}$ below the building foundation, the additional stress coefficient is $0.16-0.26$.

3.2. Settlement Calculation of the Caving Rock Mass in the Middle of the Gob. Salamon [26] researched the compaction characteristics of broken rock and determined that the stress-strain relationship of the collapsed rock mass can be calculated using formula (2).

$$
\sigma=\frac{E_{0} \varepsilon}{\left(1-\varepsilon / \varepsilon_{m}\right)}
$$

where $\sigma$ is the axial stress, $\varepsilon$ is the axial strain, $\varepsilon_{m}$ is the maximum possible strain, and $E_{0}$ is the initial tangent modulus.

The relationship [27] between $\varepsilon_{m}$ and $K_{p c}$ (residual expansion coefficient of the collapsed rock mass) and $E_{0}$ and $\sigma_{c}$ (strength of the collapsed rock mass) can be expressed by formula (3) and formula (4). Considering the effect of the additional stress caused by building loads and combining equations (2), (3), and (4), the compression settlement of the broken rock mass $\left(W_{g}\right)$ can be calculated using formula (5).

$$
\begin{aligned}
\varepsilon_{m} & =1-\frac{1}{K_{p c}}, \\
E_{0} & =\frac{10.39 \sigma_{c}^{1.042}}{K_{p c}^{7.7}}, \\
W_{g} & =h_{c} \varepsilon=h_{c} \frac{\left(\sigma+\sigma_{j}\right)\left(K_{p c}-1\right) K_{p c}^{7.7}}{10.39 \sigma_{c}^{1.042}\left(K_{p c}-1\right)+\left(\sigma+\sigma_{j}\right) K_{p c}^{8.7}},
\end{aligned}
$$

where $h_{c}$ is the height of the collapsed rock mass and $\sigma_{j}$ is the additional stresses of the building load.

According to the drilling exploration results, $h_{c}$ ranges from $7.44 \mathrm{~m}$ to $8.30 \mathrm{~m}$, with an average of $7.87 \mathrm{~m}$ and $\sigma$ values of $1.75 \mathrm{MPa}$. The measured uniaxial compressive strength of mudstone $\left(\sigma_{c}\right)$ ranges from 0.75 to $19.26 \mathrm{MPa}$, with an average of $10 \mathrm{MPa}$. The building load is $0.675 \mathrm{MPa}$, and the additional stress coefficient is 0.2 , so $\sigma_{j}$ (equal to $0.675 \mathrm{MPa}$ multiplied by 0.2 ) is $0.135 \mathrm{MPa}$. According to the observed results of fracture distribution of borehole TV imaging test, the $K_{p c}$ value is 1.1. Thus, the calculated value of $W_{g}$ is $196 \mathrm{~mm}$.

\subsection{Settlement Calculation of the Hinged Structure of the Sandstone Layer at the Gob Boundary}

3.3.1. Mechanical Analysis of the Instability of the Hinged Structure. Reference [28] pointed out that the strata above the coal pillar and near the inclined boundary of the gob fractured, forming the hinged structure of rock block $\mathrm{A}$, rock block B, and rock block C (shown in Figure 6). The fracture location is the elastic-plastic interface of the coal pillar. The coal pillar, immediate roof, and uncompacted caving rock mass are under rock block B; if the structure of rock block B 


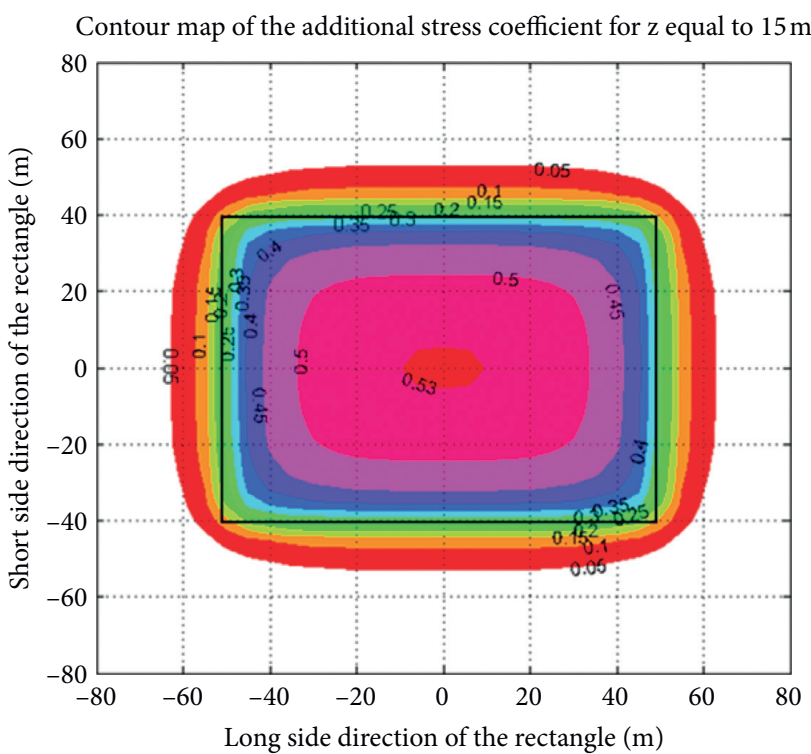

(a)

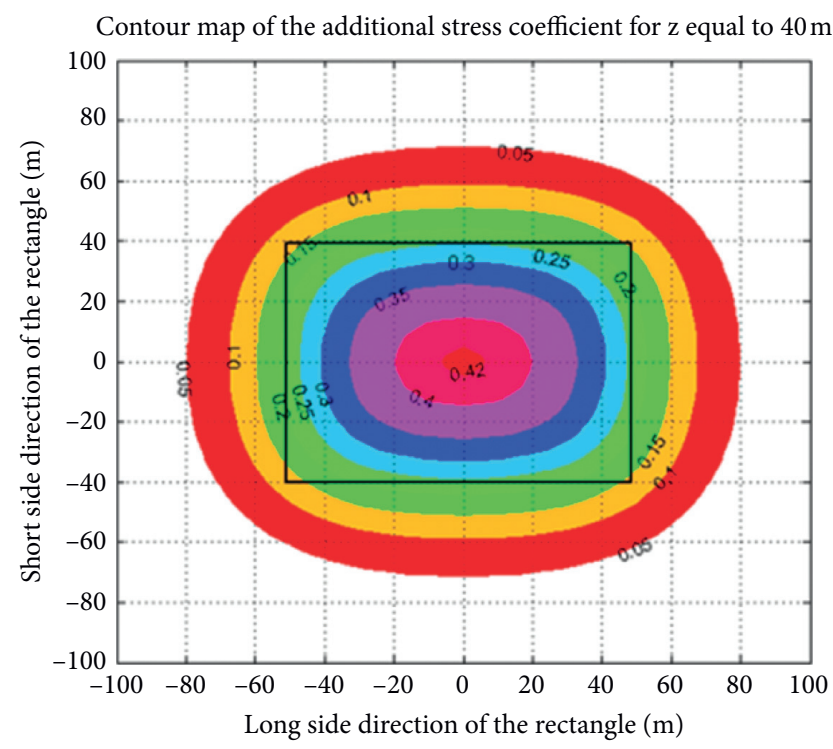

(b)

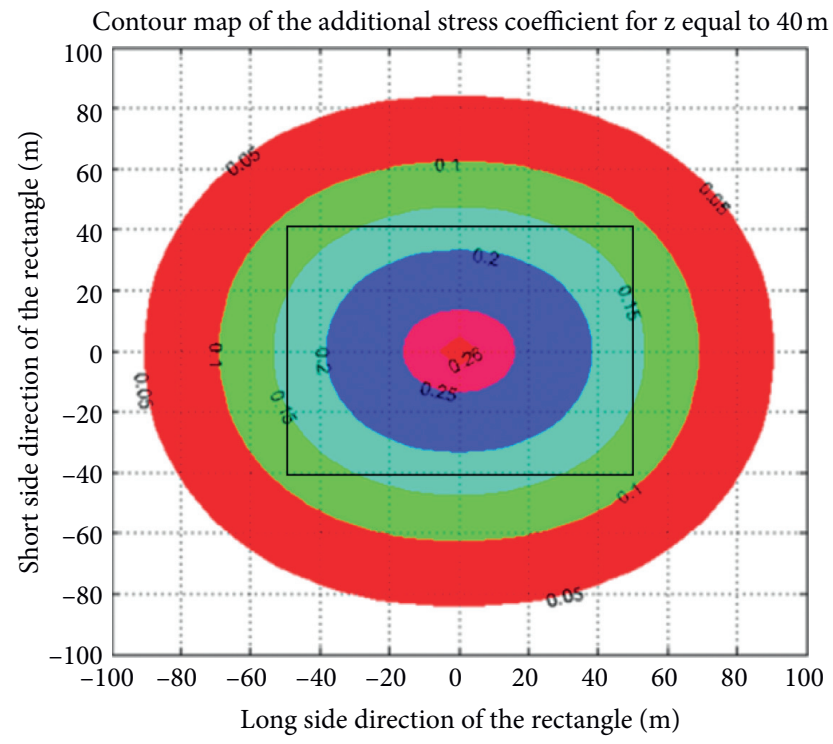

(c)

FiguRE 5: Isogram of the additional stress coefficient at different depths of foundation soil. (a) $z$ equals $15 \mathrm{~m}$; (b) $z$ equals $40 \mathrm{~m}$; (c) $z$ equals $70 \mathrm{~m}$.

loses stability under loading, sliding and rotary subsidence will occur, resulting in new subsidence. The stability of rock $\mathrm{B}$ has a great influence on the stability of the immediate roof and coal pillar.

The mechanical instability of a hinged structure is mainly rotary deformation instability or sliding instability of rock block B [29]. Reference [30] provided the "S-R" stability theory and instability criterion of hinged structures. Thus, considering the influence of additional stress due to building loads, it was determined that rock block B of the sandstone layer hinged structure below the office building would not experience rotary instability but was prone to sliding instability. After sliding instability, rock block B acts on the immediate roof, coal pillar, or caving rock below, the immediate roof is cut down, or the coal pillar ruptures when the stress exceeds the bearing limit, thus causing large settlement of rock block B.

3.3.2. Settlement Analysis of Rock Block B. According to the mechanical analysis, the subsidence of fractured rock block $\mathrm{B}$ after sliding instability can form the following two modes.

Mode 1 is the collapse of the immediate roof under rock block B on one side of the coal pillar. After sliding instability of rock block B (Figure 7(a)), the load on the immediate roof and coal pillar below increase, the suspended part of immediate roof bends, making the stress of the coal pillar in the plastic zone increase when the stress exceeds the limit, 
$q_{1}$

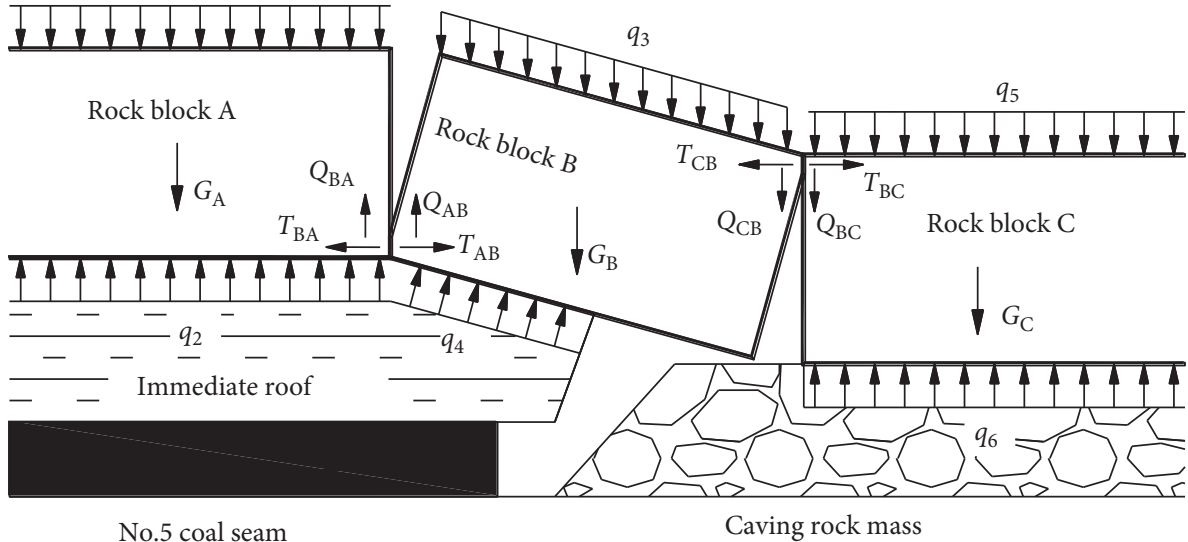

FiguRE 6: Hinged fracture structure of the sandstone layer. $G_{\mathrm{B}}$, gravity of the rock block B; $T_{\mathrm{AB}}$ and $T_{\mathrm{CB}}$, horizontal thrust of the rock block A and $\mathrm{C}$ to rock block $\mathrm{B} ; Q_{\mathrm{AB}}$ and $Q_{\mathrm{CB}}$, friction resistance of the rock block $\mathrm{A}$ and $\mathrm{C}$ to the rock block $\mathrm{B}$.

resulting in the fracture of the immediate roof and the subsidence of rock block B (Figure 7(b)). Assuming that the destructive immediate roof and coal pillar are effectively broken into blocks and filled cavities, according to the principle of space conservation, the settlement of rock block $\mathrm{B}$ can be calculated using formula (6).

$$
\Delta S=M-M \frac{x_{0}}{x_{0}+l_{0}}=M \frac{l_{0}}{x_{0}+l_{0}},
$$

where $M$ is the mining thickness, $l_{0}$ is the suspended distance of the immediate roof, $x_{0}$ is the width of the plastic zone of the coal pillar, and $\Delta S$ is the subsidence of the rock block B.

The hinged structure above both sides of the coal pillar and coal pillar failure below rock block B are referred to as mode 2. When the load of rock block B of the hinged structure on both sides acts on the immediate roof and the coal pillar (Figure 8(a)), compared with the one side (Figure 7(a)), the stress of the immediate roof and coal pillar is higher, and the coal pillar is more prone to failure than the immediate pillar. If the width of the coal pillar ( $B$ for short) is small, the overall coal pillar is destroyed (Figure $8(\mathrm{~b})$ ), and the settlement of rock block $B$ can be calculated using formula (7). However, if the width of the coal pillar is large, analogous to model 1 , the coal pillar in the plastic zone of both sides would be destroyed, and the settlement can be calculated using formula (6).

$$
\Delta S=M-M \frac{B}{B+2 l_{0}}=M \frac{2 l_{0}}{B+2 l_{0}} .
$$

3.4. Calculation of the Instability Width of the Residual Coal Pillar. The load on the coal pillar can be regarded as the sum of the load of the uncollapsed rock mass and the loose layer above (shown in Figure 9). Considering the influence of the additional stress provided by the building load, the load $\left(P_{m}\right)$ and stress $\left(\sigma_{m}\right)$ of the coal pillar can be calculated using formula (8) and formula (9).

$$
\begin{aligned}
P_{m}= & \left(B+2 l_{0}+H_{j} \cot \varphi\right) H_{j} \gamma_{j} \\
& +\left(B+2 l_{0}+2 H_{j} \cot \varphi\right) h_{s} \gamma_{s}+\sigma_{j}, \\
\sigma_{m}= & \frac{p_{m}}{B},
\end{aligned}
$$

where $H_{j}$ is the thickness of the bedrock, $\gamma_{j}$ is the average volume force of the bedrock, $h_{s}$ is the thickness of the loose layer, $\gamma_{s}$ is the average volume force of the loose layer, and $\varphi$ is the rock collapse angle.

Referencing the calculation of the limit load of the strip mining coal pillar, the limit load $\left(\sigma_{j x}\right)$ and stability coefficient $\left(K_{m}\right)$ of the residual coal pillar can be calculated using formula (10).

$$
\left\{\begin{array}{l}
\sigma_{j x}=\frac{4\left(H_{j} \gamma_{j}+h_{s} \gamma_{s}+\sigma_{j}\right)\left[B-0.00492 M\left(H_{j}+h_{s}\right)\right]}{B} \\
K_{m}=\frac{\sigma_{j x}}{\sigma_{m}}
\end{array}\right.
$$

According to the drilling exploration results and parameter values ( $l_{0}$ of $2 \mathrm{~m}, M$ of $2.5 \mathrm{~m}, \varphi$ of $70^{\circ}$, and $K_{m}$ of 1 ), the minimum stable width of the coal pillar under or without building loads is $10 \mathrm{~m}$ and $9 \mathrm{~m}$, respectively. The width of the residual coal pillar under the building ranges from 2 to $26 \mathrm{~m}$, but it is primarily less than $10 \mathrm{~m}$. The settlement of the sandstone layer at the boundary of the gob can be calculated using formula (11) for different width ranges. 


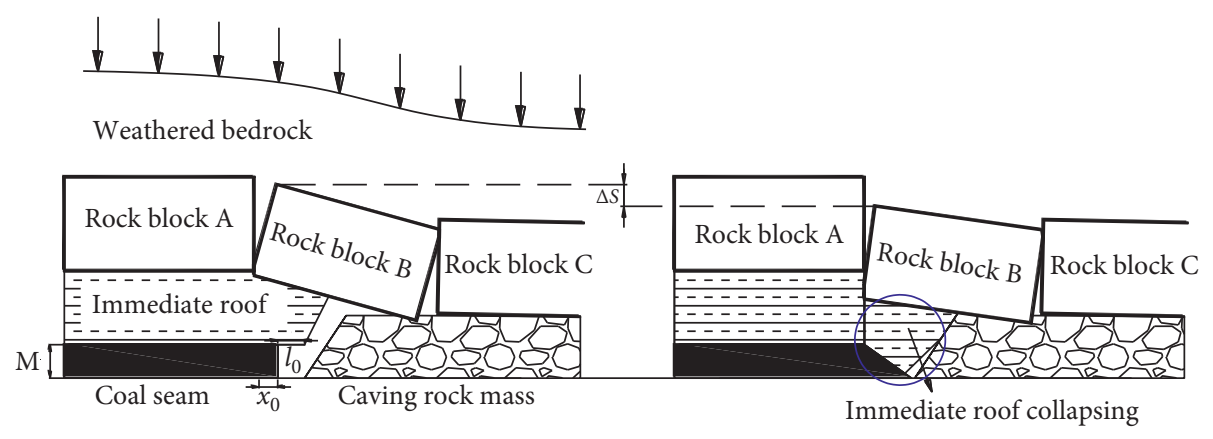

(a)

(b)

Figure 7: (a) No collapse of the immediate roof; (b) collapse of the immediate roof.

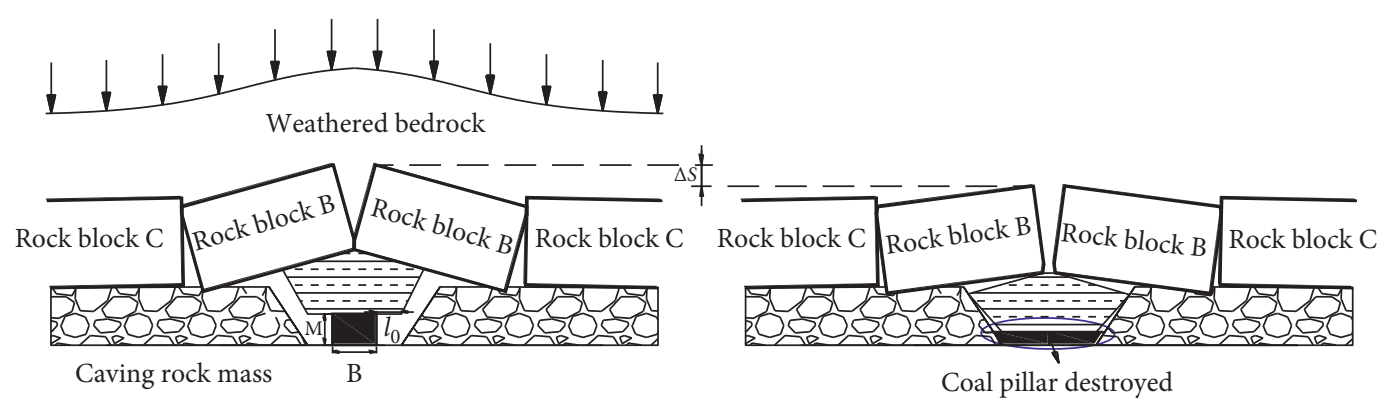

(a)

(b)

Figure 8: (a) Coal pillar is not destroyed; (b) coal pillar is destroyed.

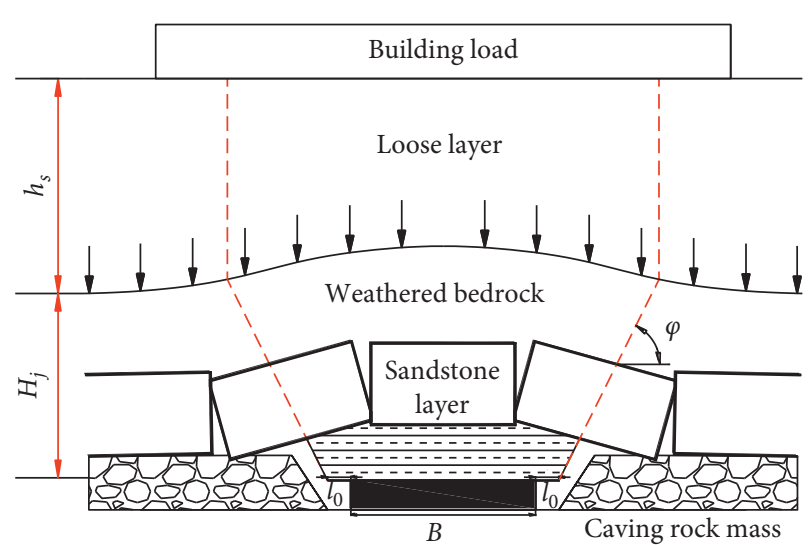

FIgURE 9: Schematic diagram of the load above the coal pillars.

$$
\Delta S= \begin{cases}h_{c} \frac{\left(\sigma+\sigma_{j}\right)\left(K_{p c}-1\right) K_{p c}^{7.7}}{10.39 \sigma_{c}^{1.042}\left(K_{p c}-1\right)+\left(\sigma+\sigma_{j}\right) K_{p c}^{8.7}}, & B \leq 9 \mathrm{~m}, \\ M \frac{2 l_{0}}{B+2 l_{0}}, & 9<B \leq 10 \mathrm{~m}, \\ M \frac{l_{0}}{x_{0}+l_{0}}, & B>10 \mathrm{~m} .\end{cases}
$$

\section{Similar Simulation Study on Cavity Distribution and Settlement of Gobs under Loads}

4.1. Design of the Experimental Schematic. The two-dimensional simulation experiment platform $(1800 \mathrm{~mm} \times 160 \mathrm{~mm} \times 1300 \mathrm{~mm})$ was adopted by taking the gobs of Xiangcheng Mine as the engineering background. According to the similarity principle and setting the geometric similarity ratio and rock strength ratio of the model to 200 and 320, respectively, the equivalent load of the building is applied by the counterweight block. In the model, the bedrock thickness is $15 \mathrm{~cm}$, the loose layer is $35 \mathrm{~cm}$, three gobs are excavated, the width of the coal pillar is $2 \mathrm{~cm}$ between two gobs, displacement measuring points ( 8 rows and 27 columns) are laid in different depths of the loose bedrock layer ( 3 rows in bedrock), and the measuring points under the central region of the load are intensively arranged. The layout and actual shapes of the model are shown in Figures 10(a) and 10(b).

\subsection{Analysis of the Results of the Simulation Experiment}

4.2.1. Distribution of Cavities in the Bedrock and Loose Layer above the Gobs after Mining. The results of the cavity distribution of the bedrock and loose layer after excavating the three gobs are shown in Figure 11. The range of the cavities is large, and the range decreases with rock mass turning and 


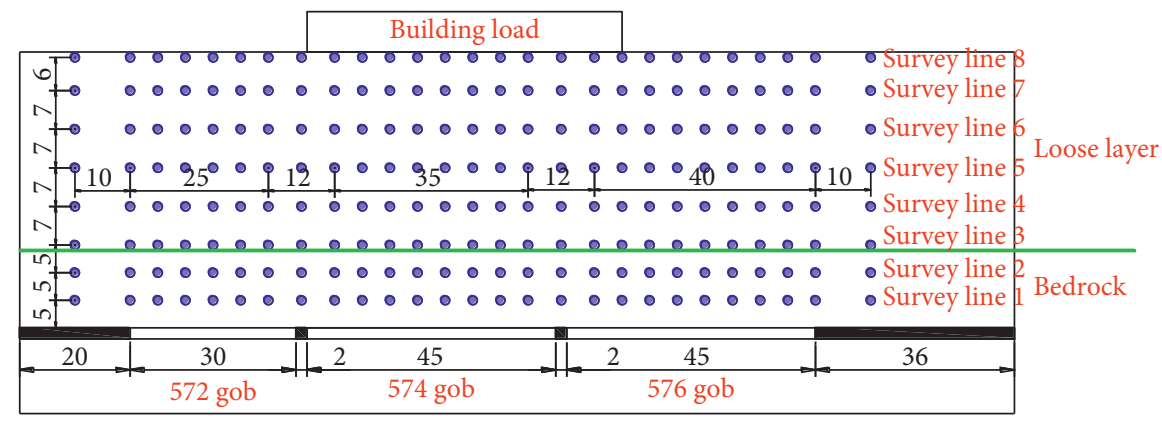

(a)

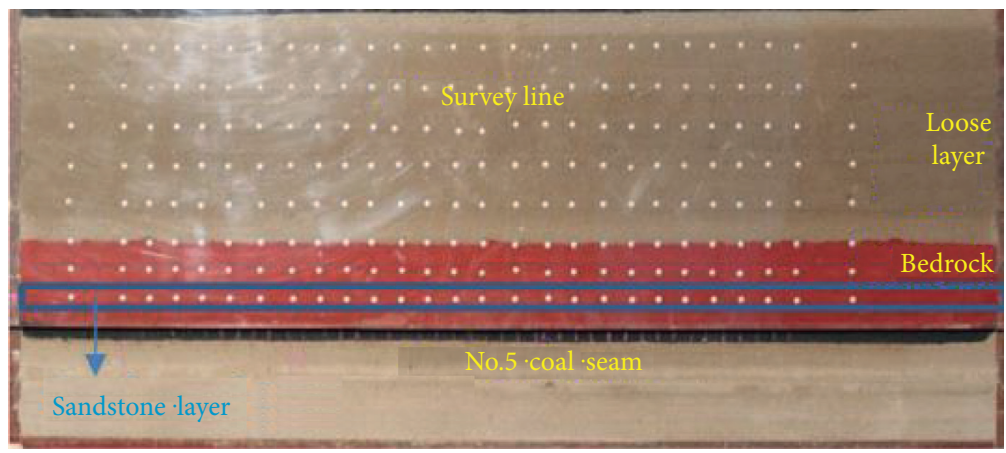

(b)

Figure 10: (a) Layout shape of the model; (b) actual shape of the model.

sliding for the hinged structure on the gob boundary. The closer to the middle of the gob is, the better the compaction is and the fewer cracks there are. There are more cavities and fractures in the caved zone, mainly the bed separation in the fracture zone, and the greater the height, the smaller the separation. With increasing mining width, the bending and fracture of rock increases, the cavity range decreases on the boundary, and the separation space decreases in the middle of the gob.

The loose layer bends and sinks with the subsidence of rock, and fractures develop upwards for a caving angle of nearly $90^{\circ}$. The loose layer has difficulty forming a structure due to the low strength; thus, continuous bending upward within the influence range of mining, fractures on both sides, and separation in the middle develop. With increasing mining time, cracks are continuously compacted.

4.2.2. Distribution of the Cavities of the Bedrock and Loose Layer above the Gobs after Building Loads Are Applied. The building load is simulated by placing the counterweight block and setting 3 load levels (laying a counterweight block for 1 to 3 layers). Under the action of the first level of loading, the upper soil layer of the loose layer is forced to compress and settle, the load is transferred to the deep soil, the fractures and separation are compacted (shown in Figure 12(b)), and the depth affected by the additional stress of the load is $30 \mathrm{~m}$. Under the second level of loading, the influence range expands downward and on both sides, the fractures and separation are continuously compacted, the affected depth is approximately $60 \mathrm{~m}$, and the bending and subsidence range of the loose layer increases. Under the third level of loading, the

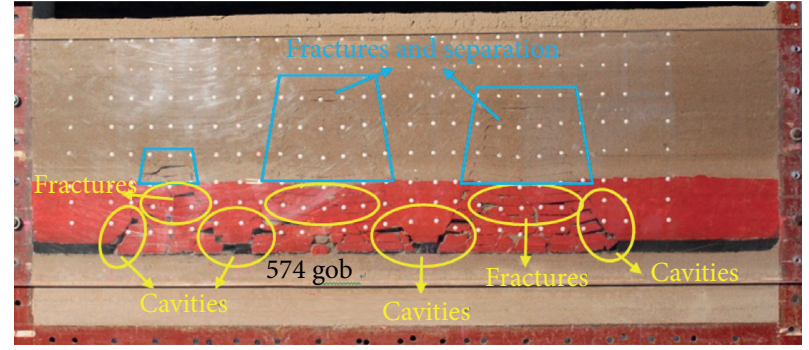

FIGURE 11: Cavities and fracture distribution of bedrock and loose layers after mining.

load influence spreads to the bedrock of the 574 gob, the strata bend and sink in the middle of the gob, so the separation decreases, and the hinged fractured rock blocks on both sides rotate and slide, so the cavities decrease. Finally, the coal pillar is broken and collapses, resulting in rapid subsidence of the upper bedrock until it is stable after contact with the rocks on both sides (Figure 12(c)).

4.2.3. Settlement of the Bedrock and Loose Layer above the Gob under Loading. The settlement change trends of the bedrock layer and loose layer in the adjacent measuring line are close, so line 1 (location in sandstone layer) and line 6 (near central depth of loose layer) are selected to analyze the settlement change in different stages. Figure 13(a) shows that the settlement of the gob and coal pillar increase under loading, but the change degree is different. Stratal separation in the bedrock decreases, and subsidence increases in the middle of the gob but decreases gradually to both sides. As the 


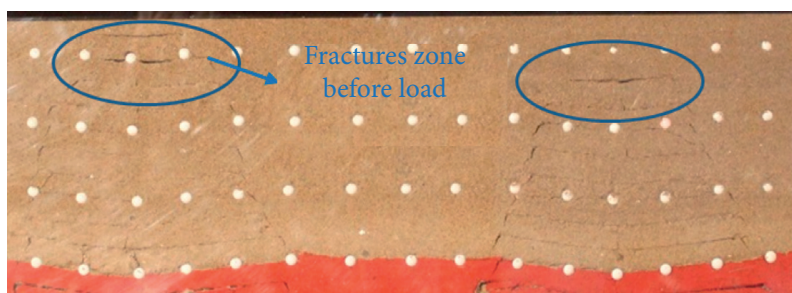

(a)

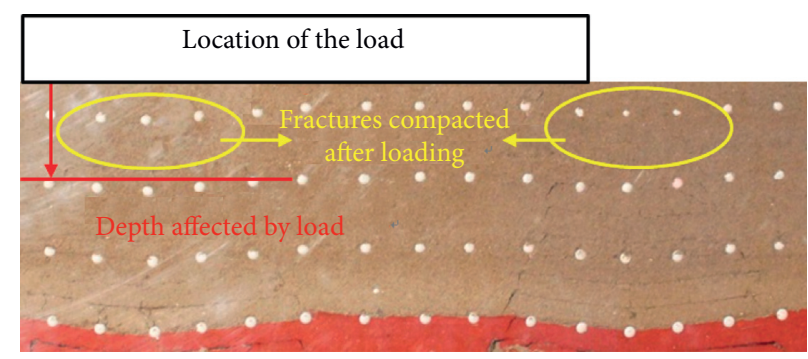

(b)

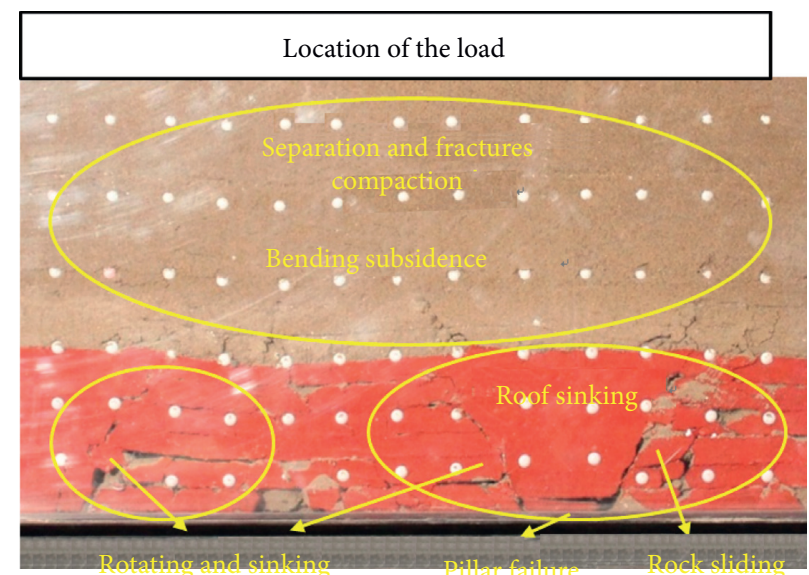

(c)

FIGURE 12: (a) Fracture distribution of the loose layer after mining; (b) fracture closure of the loose layer under the action of the first level of loading; (c) fracture distribution of the gob when coal pillar instability occurs under the third level of loading.

load increases, the settlement increases on the gob boundary for fractured rock block rotation. When the coal pillar (location from 97 to $99 \mathrm{~cm}$ ) is broken, the settlement increases from $0.41 \mathrm{~m}$ to $0.85 \mathrm{~m}$, the rock strata on both sides in the $8 \mathrm{~cm}$ range rotate and sink, and the settlement increases from $0.43 \mathrm{~m}$ to $0.53 \mathrm{~m}$. Figure 13 (b) shows that the settlement values of each measuring point in the loose layer are close when the load is small. With the increase in the load, the settlement under the load increases apparently and decreases gradually to both sides, and the bedrock subsidence increases the settlement of the loose layer. When the coal pillar is broken, the settlement of the roof and loose layer above it increases rapidly. The settlement range of the loose layer is larger than that of the gob below, and the loose layer bends and sinks within the influence range of mining and loads; thus, the settlement of the loose layer under loading can be regarded as the superposition of the compaction settlement itself and the residual settlement of the gob.

\section{Prediction of the Settlement and Deformation of the Foundation under the Building Load}

\subsection{Calculation Model of the Compression Settlement of the Foundation Soil}

5.1.1. Spatial Stress Analysis and Layered Total Settlement of the Foundation Soil. To simplify the calculation, the influence range of the rectangular load $(a \times b)$ on the foundation soil below can be regarded as a cuboid of $l_{a} \times l_{b} \times H_{z}$ (shown in Figure 14(a)). According to the design specification [31] and considering the influence of the shallow quicksand layer and gob, the regarded depth is where the additional stress is $10 \%$ of the gravity stress ( $\sigma_{z}$ for short) of the soil under the foundation, which is the depth affected by the building load $\left(H_{z}\right.$ for short, where the top is the ground). The connection line of the influence boundary on the soil surface with a load on the centerline of the long and short sides of the rectangle is calculated as the length of $l_{a}$ and $l_{b}, H_{z}$ is the maximum depth below the center point of the foundation, the spatial relationship is shown in Figure 14(b), and the vertical additional stress at any point in the affected spatial range of soil can be quickly calculated based on the analysis in Section 3.1.1.

Considering that the soil has the characteristics of stratification and compressibility, the settlement can be calculated using the layered summation method. The settlement at a point $(x, y, 0)$ on the surface of the foundation can be regarded as the accumulation of the compression settlement of each unit of soil on the straight line from the point to the depth of $H_{z}$, so the settlement value of the unit at point $(x, y, z)\left(\mathrm{d} S_{(x, y, z)}\right.$ for short $)$ and point $(x, y, 0)\left(\mathrm{S}_{(x, y, 0)}\right.$ for short) can be calculated using formula (12). It can also be divided into multiple soil layers, and each soil layer is integrated and then summing. 


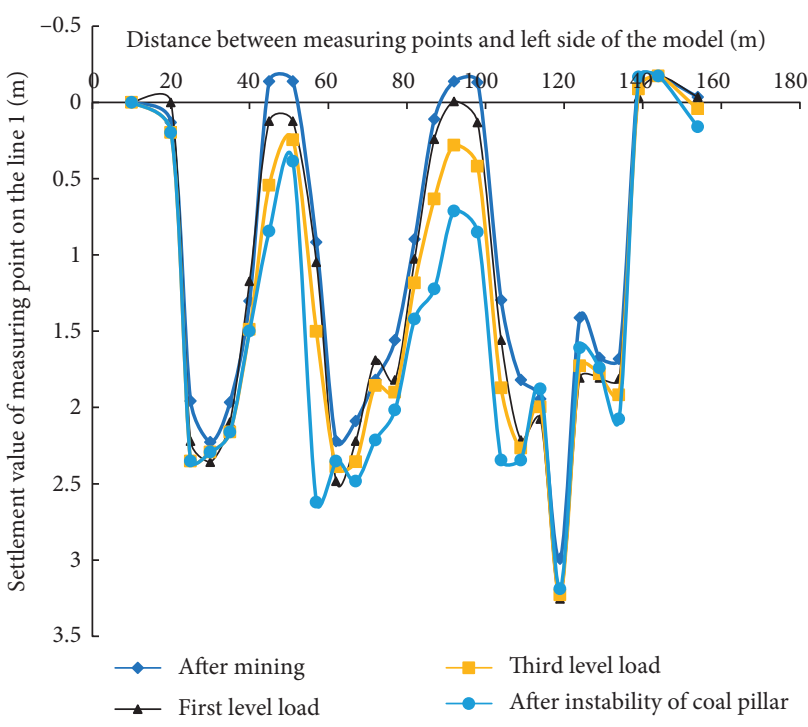

(a)

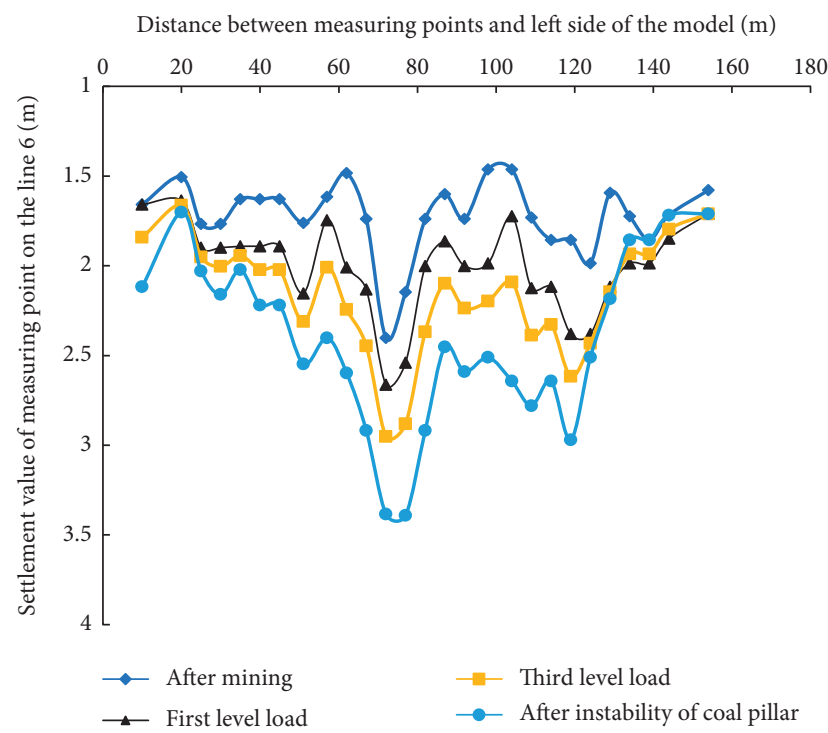

(b)

Figure 13: (a) Settlement curve of survey line 1 of the bedrock at different stages; (b) settlement curve of survey line 6 of the loose layer at different stages.

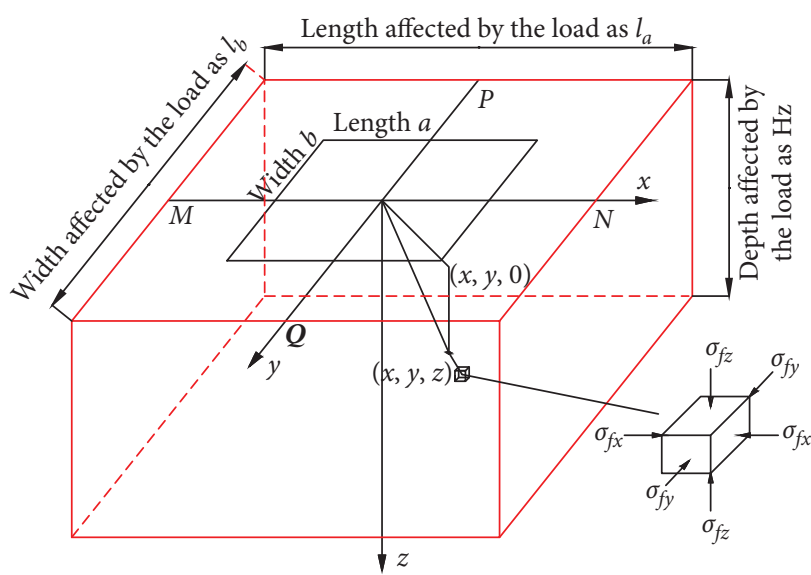

(a)

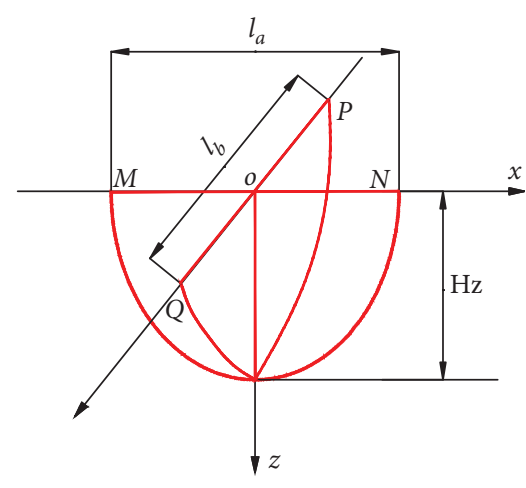

(b)

Figure 14: (a) Spatially influenced range of the foundation soil; (b) spatial relationship between $l_{a}, l_{b}$, and $H_{z}$.

$$
\left\{\begin{array}{l}
\mathrm{d} S_{(x, y, z)}=\sigma_{f z(x, y, z)} \frac{\mathrm{d} z}{E_{s(x, y, z)}}=p \alpha_{z(x, y, z)} \frac{\mathrm{d} z}{E_{s(x, y, z)}}, \\
S_{(x, y, 0)}=\int_{0}^{H_{z}} \sigma_{f z(x, y, z)} \frac{\mathrm{d} z}{E_{s(x, y, z)}}=\int_{0}^{H_{z}} p \alpha_{z(x, y, z)} \frac{\mathrm{d} z}{E_{s(x, y, z)}}
\end{array}\right.
$$

where $\alpha_{z(x, y, z)}$ is the vertical additional stress coefficient at point $(x, y, z)$ and $E_{s(x, y, z)}$ is the compression modulus of the unit soil at point $(x, y, z)$.

5.1.2. Compression Settlement under the Office Building. The thickness of the loose layer is $70 \mathrm{~m}$, and the average bulk density is $20 \mathrm{kN} / \mathrm{m}^{3}$. The maximum load of the office building is $675 \mathrm{kPa}$, taking the additional stress from the building load equal to $10 \%$ of the gravity stress of the soil as the criterion for the affected depth. The curves of the additional stress under different loads and gravity stress are shown in Figure 15. It can be seen that the greater the load, the greater the affected depth. When the building load is $675 \mathrm{kPa}$, the maximum affected depth is $78.1 \mathrm{~m}$, indicating that the additional stress affects the bedrock. Similar to the calculation of affected depth, the planerange of the influenced soil is $50 \mathrm{~m}$ extended outward from the rectangular boundary, so the space range of the influenced foundation soil is $200 \mathrm{~m} \times 180 \mathrm{~m} \times 70 \mathrm{~m}$.

Referencing the experimental data of adjacent soil samples from the Haizi mine, combined with the layered lithology, thickness, and burial depth data of the K6 borehole, the compression modulus can be calculated and seen in Table 1. 


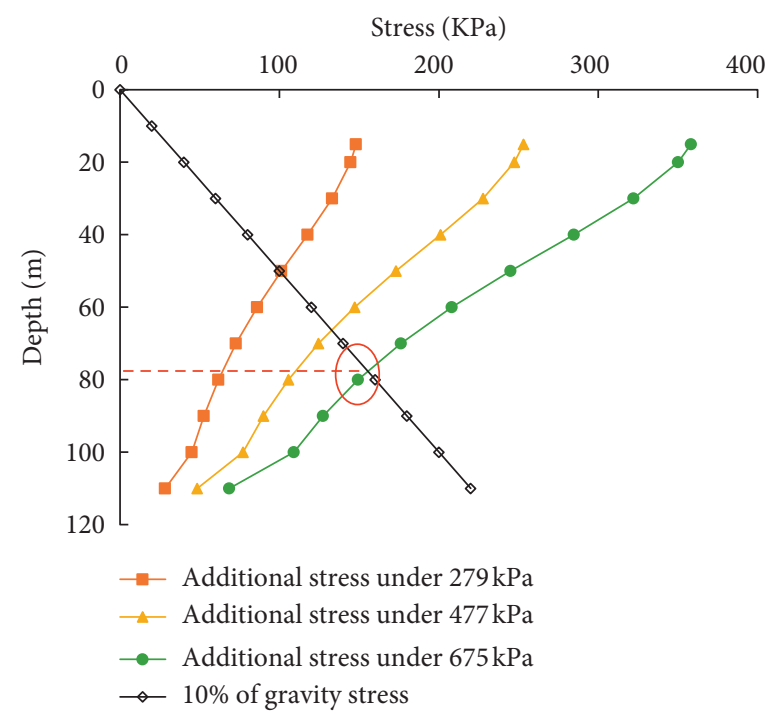

FIGURE 15: Curves of the additional stress and gravity stress of soil.

TABLE 1: Compressive modulus values of different soil layers below the construction site.

\begin{tabular}{lcccc}
\hline No. & Lithology & Thickness $(\mathrm{m})$ & Buried depth $(\mathrm{m})$ & Compression modulus $(\mathrm{MPa})$ \\
\hline 1 & Cay & 5 & 10 to 15 & 30 \\
2 & Quicksand & 5 & 15 to 20 & 24 \\
3 & Sandy clay & 6 & 20 to 26 & 50 \\
4 & Clay & 5 & 26 to 31 & 60 \\
5 & Quicksand & 1 & 31 to 32 & 24 \\
6 & Clay & 34 & 32 to 66 & 60 \\
7 & Clay gravel & 4 & 66 to 70 & 80 \\
\hline
\end{tabular}

The settlement of any point on the foundation soil surface is calculated by formula (12), and the settlement of the three-dimensional map and contours of the soil surface under the building load is obtained (shown in Figure 16). The maximum settlement of soil occurs below the load of $359 \mathrm{~mm}$ and gradually decreases from the center to the surroundings. Near the load boundary, the settlement value decreases rapidly; thus, the uneven settlement is large. The tilt curve of the soil surface in the midline of the short side of the rectangular foundation is produced (shown in Figure 16(c)). The tilt from the center to both sides first increases and then decreases, and the maximum tilt at the boundary is $14 \mathrm{~mm} / \mathrm{m}$. In the range of $20 \mathrm{~m}$ near both sides of the boundary, the change degree of tilt is the largest, indicating that the foundation is prone to uneven settlement.
5.2. Calculation of the Residual Settlement of the Gobs under the Building Load. The loose layer will be accompanied by the settlement of the sandstone layer, so the settlement of the sandstone layer can be regarded as the equivalent mining thickness $\left(M_{d}\right.$ for short). The residual settlement can be predicted by the probability integral method.

5.2.1. Prediction by the Probability Integral Method. According to the probability integral method [32], taking the equivalent mining thickness at a point $(s, t)$ in the affected area of the gob as $M_{d}(s, t)$, so the settlement at any point ( $x$, $y$ ) on the ground surface can be calculated using formula (13). Then, the tilt $\left(i_{(x, y, \varphi)}\right)$, horizontal movement $\left(U_{(x, y, \varphi)}\right)$, curvature $\left(K_{(x, y, \varphi)}\right)$, and horizontal deformation $\left(\varepsilon_{(x, y, \varphi)}\right)$ in a given $\varphi$ direction can be calculated using formula (14).

$$
\left\{\begin{array}{l}
W(x, y)=\int_{0}^{l_{A}} \int_{0}^{l_{B}} M_{d}(s, t) q_{c} \cos \alpha\left[\frac{1}{r^{2}} e^{-\pi \frac{(x-s)^{2}+(y-t)^{2}}{r^{2}}}\right] \mathrm{d} t \mathrm{~d} s \\
r=\frac{H}{\tan \beta}
\end{array}\right.
$$




$$
\left\{\begin{array}{c}
i(x, y, \varphi)=\frac{\partial W(x, y)}{\partial x} \cos \varphi+\frac{\partial W(x, y)}{\partial y} \sin \varphi \\
K(x, y, \varphi)=\frac{\partial i(x, y, \varphi)}{\partial x} \cos \varphi+\frac{\partial i(x, y, \varphi)}{\partial y} \sin \varphi \\
U(x, y, \varphi)=b \frac{\partial W(x, y)}{\partial x} \cos \varphi+b \frac{\partial W(x, y)}{\partial y} \sin \varphi \\
\varepsilon(x, y, \varphi)=\frac{\partial U(x, y, \varphi)}{\partial x} \cos \varphi+\frac{\partial U(x, y, \varphi)}{\partial y} \sin \varphi
\end{array}\right.
$$

where $q_{c}$ is the residual sinking coefficient, $H$ is the buried depth, $\alpha$ is the dip angle of coal seam, $\tan \beta$ is the main effecting angle tangent, $r$ is the radius of influence, and $b$ is the displacement factor.

\subsubsection{Affected Area of the Gob and Equivalent Mining} Thickness. The affected area of the gob, delimited by the vertical section method [33], was larger than that of the building (shown in Figure 17). According to the analysis of observation results from adjacent mines, the parameters $(\varphi$, $\delta, \gamma, \beta)$ were selected; thus, the length and width of the affected area were calculated as $291 \mathrm{~m}$ and $254 \mathrm{~m}$.

According to the distribution of gobs and coal pillars in the affected area (shown in Figure 18), combining the analysis of settlement in the middle of the gob, settlement of the fractured structure on the boundary, and settlement of the broken coal pillars, the affected area can be divided into four types, including the midarea $\left(M_{d}\right.$ values of $\left.196 \mathrm{~mm}\right)$, coal pillar instability area $\left(M_{d}\right.$ values of $\left.196 \mathrm{~mm}\right)$, coal pillar stability area $\left(M_{d}\right.$ values of $\left.196 \mathrm{~mm}\right)$, and potential subsidence area $\left(M_{d}\right.$ values of $\left.1250 \mathrm{~mm}\right)$.

5.2.3. Calculation Results of the Residual Settlement and Deformation of the Gobs. The parameters of the probability integral method are selected based on the similarities with the data of adjacent mines (shown in Table 2). The residual settlement, tilt, curvature, and horizontal deformation of the gob were calculated according to the range of different regions and the equivalent mining thickness in the affected area of the gob, and the contour maps of the settlement and tilt are shown in Figures 19 and 20 . According to the contour, the maximum settlement, tilt, curvature, and horizontal deformation below the building foundation were $196 \mathrm{~mm}, 1.45 \mathrm{~mm} / \mathrm{m}, 0.06\left(10^{-3} / \mathrm{m}\right)$, and $1.44 \mathrm{~mm} / \mathrm{m}$, respectively.

\subsection{Prediction of the Total Settlement and Deformation of the} Foundation. The total settlement of the foundation can be regarded as the vector superposition of the compressive settlement of the soil and residual settlement of the gob. Using the calculation coordinate system of the residual settlement, the total settlement $\left(S_{f t}(x, y)\right)$ can be calculated using formula (15). Then, the tilt $\left(i_{(x, y, \varphi)}\right)$, curvature $\left(K_{(x, y, \varphi)}\right)$, and horizontal deformation $\left(\varepsilon_{(x, y, \varphi)}\right)$ in a given $\varphi$ direction can be calculated using formula (16). Thus, the maximum total settlement, tilt, curvature, and horizontal deformation below the building foundation were $555 \mathrm{~mm}, 14.9 \mathrm{~mm} / \mathrm{m}$, $0.06\left(10^{-3} / \mathrm{m}\right)$, and $1.44 \mathrm{~mm} / \mathrm{m}$, respectively.

$$
\begin{aligned}
S_{f t}(x, y) & =S\left(x-0.5 l_{A}, 0.5 l_{B}-y\right)+W(x, y, 0) \\
& =\int_{0}^{H_{z}} p \alpha_{z\left(x-0.5 l_{A}, y, z\right)} \frac{d z}{E_{s(x, y, z)}}+\int_{0}^{l_{A}} \int_{0}^{l_{B}} M_{d}(s, t) q_{c} \cos \alpha\left[\frac{1}{r^{2}} e^{\left.-\pi \frac{(x-s)^{2}+(y-t)^{2}}{r^{2}}\right] \mathrm{d} t \mathrm{~d} s}\right. \\
& \left\{\begin{array}{l}
i_{f t}(x, y, \varphi)=\frac{\partial S_{f t}(x, y)}{\partial x} \cos \varphi+\frac{\partial S_{f t}(x, y)}{\partial y} \sin \varphi \\
K_{f t}(x, y, \varphi)=\frac{\partial i_{f t}(x, y, \varphi)}{\partial x} \cos \varphi+\frac{\partial i_{f t}(x, y, \varphi)}{\partial y} \sin \varphi \\
U_{f t}(x, y, \varphi)=b \frac{\partial S_{f t}(x, y)}{\partial x} \cos \varphi+b \frac{\partial S_{f t}(x, y)}{\partial y} \sin \varphi \\
\varepsilon_{f t}(x, y, \varphi)=\frac{\partial U_{f t}(x, y, \varphi)}{\partial x} \cos \varphi+\frac{\partial U_{f t}(x, y, \varphi)}{\partial y} \sin \varphi
\end{array}\right.
\end{aligned}
$$




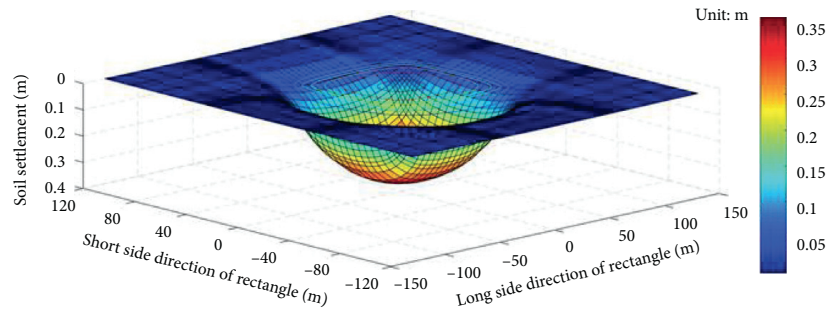

(a)

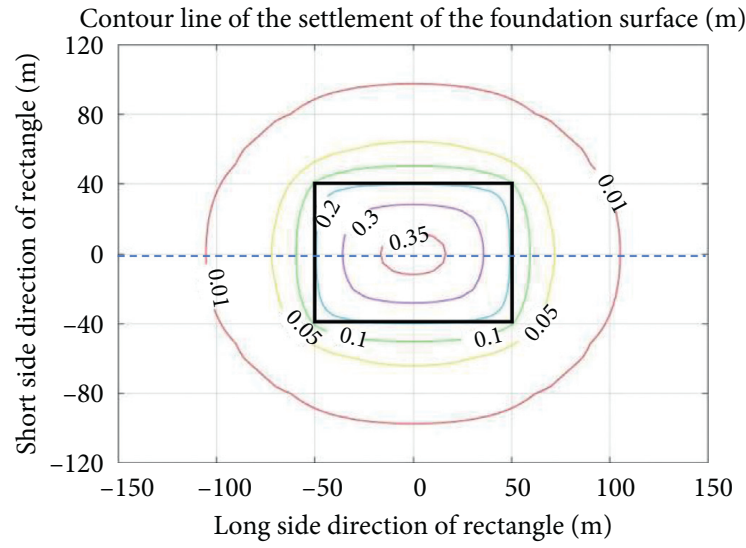

(b)

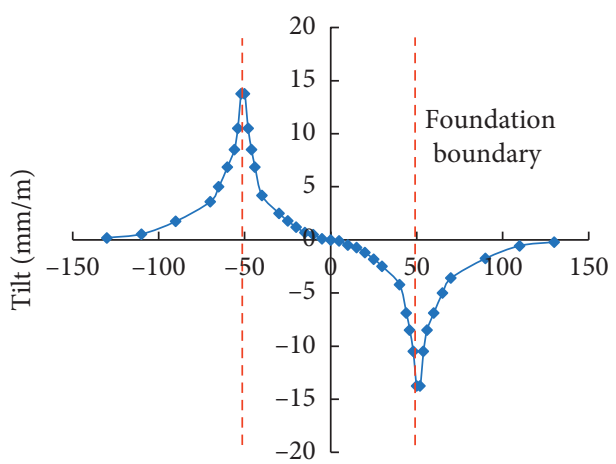

Long side direction of rectangle $(\mathrm{m})$

(c)

Figure 16: (a) Three-dimensional map of the settlement of the foundation surface; (b) contour line of the settlement of the foundation surface; tilt slope curve of the foundation line of the long and short sides of the rectangle.

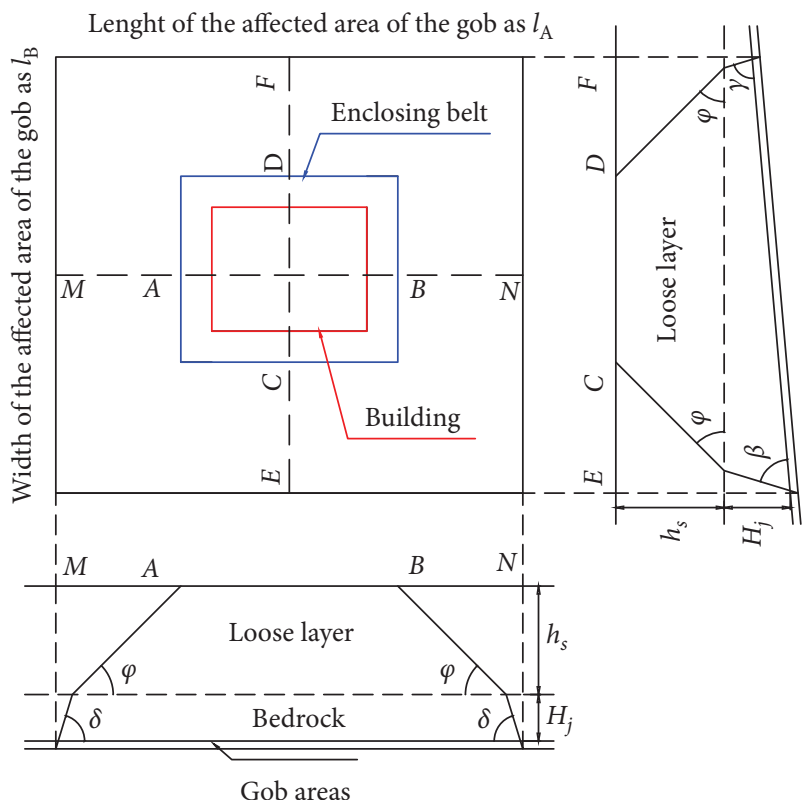

FIGURE 17: Vertical section method for determining the affected area of the gob $\varphi$, movement angle of loose layer; $\delta$, strike movement angle of bedrock; $\gamma$, uphill movement angle of bedrock; $\beta$, downhill movement angle of bedrock; $h_{s}$, thickness of loose layer; $H_{j}$, thickness of bedrock.

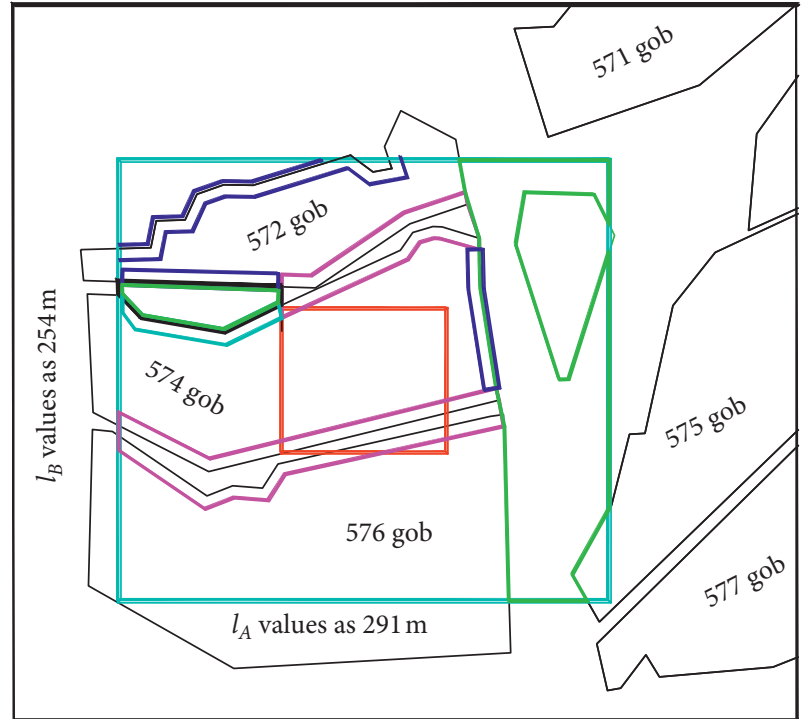

Office building boundary

Affected area boundary of gob

Coal pillar instability area

obs boundary

Coal pillar stability area

Potential subsidence area

Figure 18: Affected area below the office building. 
TABLE 2: Parameters of surface movement.

\begin{tabular}{lc}
\hline Calculated parameters & Value \\
\hline Subsidence factor & 1 \\
Main affecting angle tangent & 1.42 \\
Displacement factor & 0.34 \\
Mining affecting the propagation angle & 89 \\
Inflection point offset & 0 \\
\hline
\end{tabular}

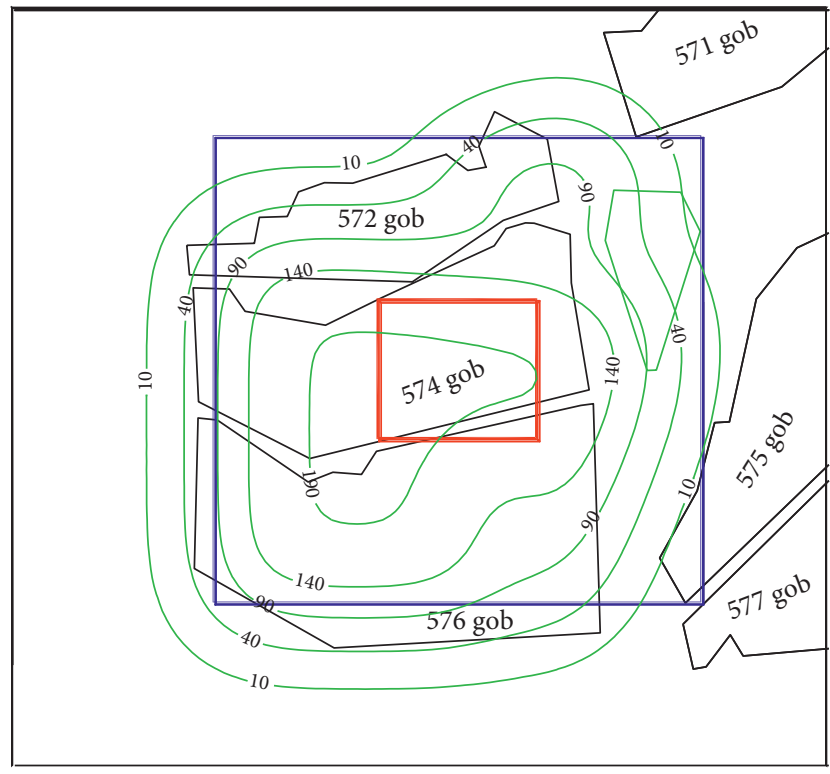

Office building boundary Affected area boundary of gob

Gobs boundary _ Subsidence equivalent curve

FIGURE 19: Contour map of the residual settlement of gobs below the office building (unit $\mathrm{mm}$ ).

\section{Stability Analysis and Treatment Measures of the Large Building Foundation}

\subsection{Stability Evaluation of the Foundation}

6.1.1. Relationship between the Influence of the Building Load and Fracture Zone of the Gob. According to the analysis of the affected depth based on the building load and observation result of the fracture zone height $\left(H_{l i}\right.$ for short) of the ZK6 borehole under the foundation, the maximum affected depth is $78.1 \mathrm{~m}$, the height of the fractured zone is $12.6 \mathrm{~m}$, and the affected depth has not reached the fractured zone, but the distance is only $8.7 \mathrm{~m}$ between the two which is less than the empirical value of $10 \mathrm{~m}$; therefore the gob will cause the instability of the foundation.

6.1.2. Analysis of the Settlement and Deformation of the Foundation. The maximum settlement and deformation of the foundation below the office building are shown in Table 3. According to the specification [31], the permissible settlement is $200 \mathrm{~mm}$, and the permissible tilt is $2 \mathrm{~mm} / \mathrm{m}$ for

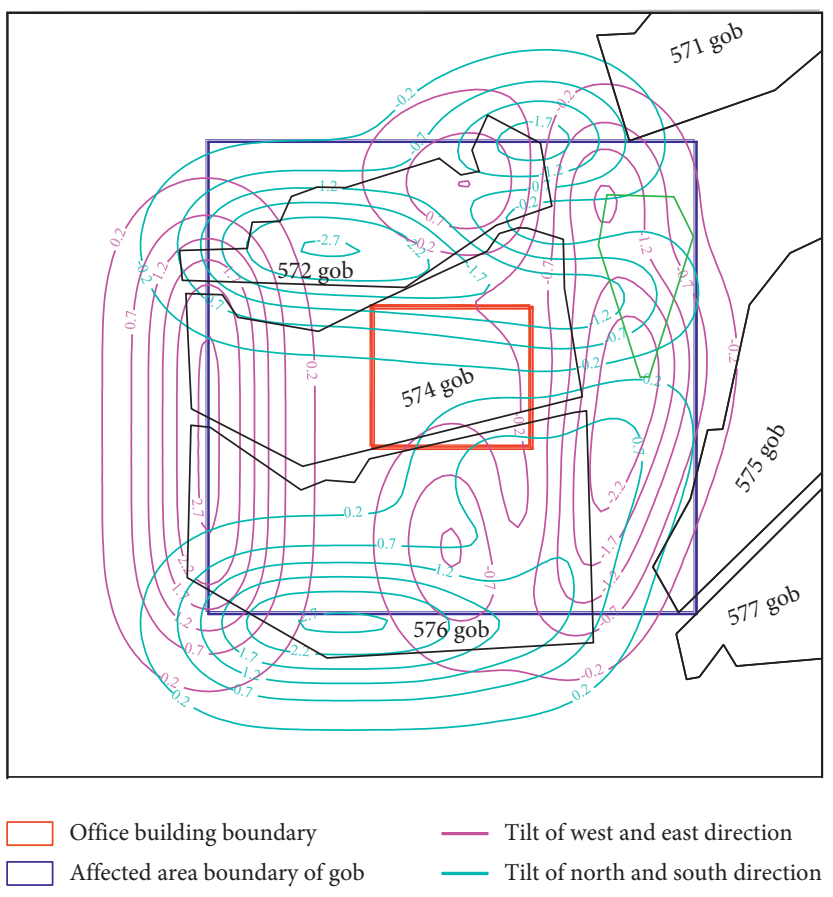

Figure 20: Contour map of the tilt of gobs below the office building (unit $\mathrm{mm} / \mathrm{m}$ ).

a high-rise building. The maximum settlement $(359 \mathrm{~mm}$ ) and tilt $(14 \mathrm{~mm} / \mathrm{m})$ of the soil are greater than the permissible value, and the maximum residual settlement $(196 \mathrm{~mm})$ and tilt $(1.45 \mathrm{~mm} / \mathrm{m})$ of the gob are close to the permissible value, indicating that the compression of loose soil has a great influence on the foundation, and the risk is greater after superposition; therefore, the stability of the building foundation is poor. The foundation is prone to large settlement and uneven tilt damage without treatment measures.

6.2. Treatment Measures. Due to the large thickness of the loose layer below the construction site, the compression settlement of the soil under the building load is large. Additionally, there are several flow sand layers (approximate overall thickness of $11 \mathrm{~m}$ ) in the shallow soil from 15 to $30 \mathrm{~m}$, which are prone to shear slip due to seepage, thus increasing the uneven settlement of the soil. Considering that there are clay and clay gravel layers in the buried depth from 40 to $70 \mathrm{~m}$ of the loose layer with a high degree of consolidation and low compressibility, the pile group foundation is adopted, and the depth of the pile is $50 \mathrm{~m}$, which passes through the flowing sand layers to transfer the load to the deep soil layer, thus effectively reducing soil settlement.

Grouting reinforcement in the gob is an effective measure to control residual settlement. The cement-fly ash slurry is injected into the gob through drilling to fill the cavities and fractures in the caved zone and fracture zone, thus reducing the residual settlement of the gob. 
TABle 3: Maximum settlement and deformation of the foundation below the office building.

\begin{tabular}{lcccc}
\hline Classification & \multicolumn{3}{c}{ Maximum values } \\
Settlement $(\mathrm{mm})$ & Tilt $(\mathrm{mm} / \mathrm{m})$ & Curvature $\left(10^{-3} / \mathrm{m}\right)$ & Horizontal deformation $(\mathrm{mm} / \mathrm{m})$ \\
\hline Compression settlement of soil & 359 & 14 & - & - \\
Residual settlement of gobs & 196 & 1.45 & 0.06 & 1.44 \\
Vector overlay & 555 & 14.9 & 0.06 & 1.44 \\
\hline
\end{tabular}

\section{Conclusions}

Through the detection results of borehole drilling and color drilling TV observations of gobs, the bedrock structure over the gob can be divided into the weathered bedrock layer, fractured sandstone layer (key layer), and collapsed mudstone (immediate roof) layer. There is still some range of cavities and fractures in the caved zone in the middle of the gob, and the space increases near the boundary, which is the main space of residual settlement in the gob.

The maximum compressive settlement of the foundation soil below the office building is $359 \mathrm{~mm}$, and the settlement is relatively uniform in the center area but the settlement and the tilt change greatly when being close to the load boundary. The maximum tilt is $14 \mathrm{~mm} / \mathrm{m}$, and the foundation is prone to generate uneven settlement near the boundary. Based on the random medium theory and equivalent mining height theory, the maximum residual settlement and tilt of the gob under the building load are $196 \mathrm{~mm}$ and $1.45 \mathrm{~mm} / \mathrm{m}$, respectively.

The total settlement of the foundation can be regarded as the vector superposition of the compression settlement and residual settlement. The maximum total settlement is $555 \mathrm{~mm}$, and the maximum tilt is $14.9 \mathrm{~mm} / \mathrm{m}$ of the foundation under the building load, which are greater than the permissible values $(200 \mathrm{~mm}$ and $2 \mathrm{~mm} / \mathrm{m}$, resp.). In addition, the depth affected by the building load is less than $9 \mathrm{~m}$ from the top of the fracture zone, so the stability of the gob areas is poor. This indicates that the stability of the building foundation at the construction site was adverse; therefore, governance measures are necessary.

A deep pile group foundation (pile tip depth $50 \mathrm{~m}$ ) is used to go through the flow sand layer in the shallow soil to transmit the load to the deep clay layer with small compressibility, thus effectively reducing the uneven settlement of the soil. In addition, grouting slurry fills cavities and cracks in the caved zone and fracture zone of gob areas, thus effectively reducing the residual settlement. The two treatment measures can effectively improve the stability of the building foundation.

\section{Data Availability}

The data used to support the findings of this study are included within the article partly or available from the corresponding author upon request.

\section{Conflicts of Interest}

The authors declare that there are no conflicts of interest regarding the publication of this paper.

\section{Acknowledgments}

The authors acknowledge Tiandi Science and Technology Co., Ltd. for providing the project data. Support from the Special Project of Science and Technology Innovation Fund of China Coal Technology and Engineering Group (no. 2019-ZD004), National Science and Technology Major Project (no. 2016ZX05068002-003), and National Natural Science Foundation of China (no. 51804162) is also gratefully acknowledged.

\section{References}

[1] S. W. Adator and J. F. Li, "Evaluating the environmental and economic impact of mining for post-mined land restoration and land-use: a review," Journal of Environmental Management, vol. 279, 2021.

[2] B. N. Hu and W. Y. Guo, "Mining subsidence area status, syntheses governance model and governance recommendation," Coal Mining Technology, vol. 23, no. 2, pp. 1-4, 2018, in Chinese.

[3] S. Z. Li, "Studying and application of key technology of urban construction in mining subsidence area," Coal Mining Technology, vol. 21, no. 2, pp. 73-77, 2016, in Chinese.

[4] G. G. Marino and W. Gamble, "Mine subsidence damage from room and pillar mining in Illinois," International Journal of Mining and Geological Engineering, vol. 4, no. 2, pp. 129-150, 1986.

[5] R. E. Gray, R. W. Bruhn, and R. J. Turka, "Study and analysis of surface subsidence over the mined Pittsburgh coalbed," International Journal of Rock Mechanics and Mining Sciences \& Geomechanics Abstracts, vol. 5, no. 6, p. 131, 1977.

[6] K. M. Han, F. M. Li, and J. W. Cheng, "Fuzzy comprehensive evaluation for stability of strata over gob influenced by construction loads," Energy Procedia, vol. 16, pp. 1102-1110, 2012.

[7] Y. H. Teng, Z. X. Tang, S. H. Li et al., "Evaluation of foundation stability in coal mine subsidence area and deformation resistance technology," in Proceedings of International Conference on Geoinformatics, pp. 1-4, Marseille, France, August 2017.

[8] V. André, "Various phases in surface movements linked to deep coal longwall mining: from start-up till the period after closure," International Journal of Coal Science \& Technology, vol. 55, 2020.

[9] V. Palchik, "Formation of fractured zones in overburden due to longwall mining," Environmental Geology, vol. 44, no. 1, pp. 28-38, 2003.

[10] W. Y. Lu, C. C. He, and X. Zhang, "Height of overburden fracture based on key strata theory in longwall face," PLoS One, vol. 15, no. 1, 2020.

[11] W. B. Guo, G. B. Zhao, and G. Z. Lou, "Height of fractured zone inside overlying strata under high-intensity mining in 
China," International Journal of Mining Science and Technology, vol. 29, no. 1, pp. 45-49, 2019.

[12] Y. Guéguen, B. Deffontaines, B. Fruneau et al., "Monitoring residual mining subsidence of Nord/Pas-de-Calais coal basin from differential and persistent scatterer interferometry (Northern France)," Journal of Applied Geophysics, vol. 69, no. 1, pp. 24-34, 2009.

[13] W. Y. Guo, S. Q. Liu, B. N. Hu et al., "Grouting reinforcement of large building foundation over old gob areas: a case study in Huaibei mining area, China," Advances in Civil Engineering, vol. 2018, Article ID 8738752, 11 pages, 2018.

[14] F. Du, K. Wang, X. Zhang et al., "Experimental study of coalgas outburst: insights from coal-rock structure, gas pressure and adsorptivity," Natural Resources Research, vol. 29, pp. 2481-2493, 2020.

[15] C. Zhang, S. Tu, and Y. Zhao, "Compaction characteristics of the caving zone in a longwall goaf: a review," Environ Earth Science, vol. 78, no. 27, 2019.

[16] K. Wang and F. Du, "Experimental investigation on mechanical behavior and permeability evolution in coal-rock combined body under unloading conditions," Arabian Journal of Geosciences, vol. 12, p. 422, 2019.

[17] Q. B. Guo, X. R. Meng, Y. M. Li et al., "A prediction model for the surface residual subsidence in an abandoned goaf for sustainable development of resource-exhausted cities," Journal of Cleaner Production, vol. 279, 2021.

[18] B. N. Wang, F. N. Dang, W. Chao et al., "Surrounding rock deformation and stress evolution in pre-driven longwall recovery rooms at the end of mining stage," International Journal of Coal Science \& Technology, vol. 6, no. 4, pp. 536546, 2019.

[19] P. Xu, X. B. Mao, M. X. Zhang et al., "Safety analysis of building foundations over old goaf under additional stress from building load and seismic actions," International Journal of Mining Science and Technology, vol. 24, no. 5, pp. 713-718, 2014.

[20] E. F. Salmi, M. Nazem, and M. Karakus, "The effect of rock mass gradual deterioration on the mechanism of post-mining subsidence over shallow abandoned coal mines," International Journal of Rock Mechanics and Mining Sciences, vol. 91, pp. 59-71, 2017.

[21] J. L. Wang, C. J. Ding, Y. Zhang et al., "Numerical analysis of effect of abandoned goaf foundation deformation on ground buildings," Journal of Mining \& Safety Engineering, vol. 25, no. 4, pp. 476-480, 2008.

[22] H. Y. Wang, X. Y. Fang, F. Du et al., "Three-dimensional distribution and oxidation degree analysis of coal gangue dump fire area: a case study," Science of The Total Environment, vol. 772, 2021.

[23] X. Zhang, H. Yu, J. Dong et al., "A physical and numerical model-based research on the subsidence features of overlying strata caused by coal mining in Henan, China," Environ Earth Science, vol. 76, 2017.

[24] Z. Q. Yang, C. Liu, H. Z. Zhu et al., "Mechanism of rock burst caused by fracture of key strata during irregular working face mining and its prevention methods," International Journal of Mining Science and Technology, vol. 29, no. 6, pp. 889-897, 2019.

[25] R. D. Mindlin, "Force at a point in the interior of a semiinfinite solid," Physics, vol. 7, no. 5, pp. 195-202, 1936.

[26] M. D. G. Salamon, "Rock mechanics contributions and challenges," in Proceedings of the31st US Symposium, pp. 161-168, Golden, Colorado, April 1990.
[27] D. M. Pappas and C. Mark, Behaviour of simulated longwall gob material, Report of Investigations, US Department of the Interior, Washington, DC, USA, 1993.

[28] Y. C. Wan, "Practices on bolt and grouting support technology for mine high stressed roadway in deep mine," Coal Science and Technology, vol. 33, no. 10, pp. 17-19, 2005, in Chinese.

[29] M. G. Qian and P. W. Shi, Ground Pressure and Strata Control, China University of Mining and Technology Press, Xuzhou, China, 2003, in Chinese.

[30] M. G. Qian, F. L. He, Z. T. Wang et al., "A further discussion on the theory of the strata behaviors in longwall mining," Journal of China University of Mining \& Technology, vol. 23, no. 3, pp. 1-9, 1994, in Chinese.

[31] Ministry of Construction of the People's Republic of China, Code for Design of Building Foundation, China Building Industry Press, Beijing, China, 2011, in Chinese.

[32] L. Y. Wang, K. Z. Deng, and M. N. Zheng, "Research on ground deformation monitoring method in mining areas using the probability integral model fusion D-InSAR, subband InSAR and offset-tracking," International Journal of Applied Earth Observation and Geoinformation, vol. 85, Article ID 101981, 2020.

[33] State Bureau of Coal Industry, Regulations of Coal Pillar Set and Mining of Building, Water Body, Railway and Main Well Lane, China Coal Industry Publishing House, Beijing, China, 2000, in Chinese. 